\title{
Génesis de la Nueva Evangelización en América Latina
}

\section{INTRODUCCION: JUAN PABLo II Y LA NUEVA EVANGELIZACION}

En la historia de América Latina, durante los últimos decenios, se ha iniciado una nueva etapa de la evangelización de la Iglesia en el continente, que se ha comenzado a designar como "la Nueva Evangelización", y que se ha constituido en el tema central de la IV Conferencia General del Episcopado Latinoamericano, que se celebrará en el próximo mes de octubre de Santo Domingo.

La formulación de Nueva Evangelización, aunque no exenta de algunas críticas y reticencias, ha tenido una significativa consolidación y un constante proceso de profundización y clarificación, desde que fue propuesta por Juan Pablo II en Haití en marzo de 1983. Consciente de la realidad de América Latina describe a su pueblo con dos características fundamentales: Como "un pueblo profundamente religioso, que pide el pan de la Palabra de Dios, pues en El pone su confianza", y como "un pueblo que sufre", debido a "hirientes injusticias, explotación de unos por otros, falta grave de equidad en la distribución de las riquezas y de los bienes de la cultura". En este contexto proponía que "la conmemoración del medio milenio de evangelización tendrá su significación plena si es un compromiso vuestro como obispos, junto con vuestro presbiterio y fieles; compromiso no de reevangelización, pero sí de una evangelización nueva. Nueva en su ardor, en sus métodos, en su expresión" 1 .

A partir de este momento, el proyecto de la Nueva Evangelización se constituye en tema céntrico de las orientaciones pastorales que Juan Pablo II durante estos años ha ido impartiendo constantemente a las Iglesias de

1. Ecclesia 2119 (1983) 413-415. 
América Latina ${ }^{2}$ El 12 de diciembre de 1990, al aprobar el tema de la IV Conferencia recordaba, a través del Cardenal Gantin que "nueva evangelización es el elemento englobante, la idea central e iluminadora" 3 .

Simultáneamente ha ido ampliando el proyecto para toda la Iglesia. Ya en diciembre de 1985, propone un compromiso para "toda la Iglesia, a nivel diría cósmico, proyectada hacia Nueva Evangelización misionera, según el impulso que le ha sido otorgado, ad intra y ad extra, por las consignas del Vaticano II, retomadas e irradiadas por el Sínodo de los Obispos" ${ }^{4}$. Posteriormente, en 1988, con horizontes planetarios, con compromisos paneclesiales y recogiendo las intuiciones de la Evangelii Nuntiandi lo ha vuelto a proponer en la Exhortación Apostólica Cristifideles laici (ChL 34-44).

Ante este fenómeno eclesial, extraordinariamente complejo, y al que he cualificado en otras ocasiones como "el primer proyecto de una evangelización orgánica de toda la Iglesia ad intra y ad extra", sólo me voy a detener en tres puntos en esta comunicación.

En primer lugar pretendo clarificar que la Nueva Evangelización originalmente es un proyecto autóctono y propio de las Iglesias de América, que se viene elaborando y desarrollando durante largos años.

En segundo lugar, presentaremos esquemáticamente el contenido actual del proyecto, en vísperas de la celebración de la IV Conferencia, teniendo en cuenta el Documento de Trabajo recientemente elaborado, lo mismo que otras importantes aportaciones.

Por último, examinaré la incidencia que el proyecto latinoamericano puede tener en la misión evangelizadora de la Iglesia Universal de hoy, abierta a los desafíos del tercer milenio.

\section{La Nueva Evangelizacion: un Movimiento Autoctono de las Igle-} SIAS DE AMÉRICA LATINA.

Hoy, cuando Juan Pablo II se ha constituido en el gran promotor e impulsor de la Nueva Evangelización en todả la Iglesia, puede resultar extraño el definirla como un movimiento originalmente autóctono de las Iglesias de América Latina.

Y sin embargo es así. El movimiento surge en América Latina hace varias décadas, inicialmente sin nombre, ante la nueva situación epocal en la que se

2. G. Melguizo, "La Nueva Evangelización en el magisterio de Juan Pablo II", en AA.VV., "Hacia la Cuarta Conferencia”, Eds. CELAM, Bogotá 1992, pp. 165-169.

3. L'Osservatore Romano, 14/12/90 p. 1.

4. Ecclesia 2251 (1986) 27. 
encuentra el continente y sus archipiélagos. Se desarrolla progresivamente, pretendiendo ser fiel a las enseñanzas y valores positivos de su evangelización fundante, y manteniendo un constante diálogo con las nuevas aportaciones de la Iglesia Universal y especialmente con la Iglesia de Roma. A través de los años, el movimiento se ha hecho vida, reflexión, documentos y nombre. Es lo que aparece ante el Papa el 28 de enero de 1979, en su primer encuentro con las Iglesias Latinoamericanas en la Conferencia de Puebla.

\section{Confirma en la fe a tus hermanos}

En efecto, la expresión "Nueva Evangelización” surge por vez primera en América Latina, en la crucial Conferencia de Medellín. Los Obispos, en su último mensaje, proponen como compromiso a todo el Pueblo de Dios "alentar una nueva evangelización y catequesis intensivas que lleguen a las élites y a las masas para logar una fe lúcida y comprometida". Es evidente, por el contexto, el sentido restrictivo y kerygmático, generalizado antes de la promulgación de la Evangelii Nuntiandi, que los Obispos daban a la palabra evangelización, sobre todo teniendo en cuenta sus afirmaciones en el Documento de Pastoral Popular (n. 8).

Pero, el término vuelve a aparecer en Puebla con una precisión muy ajustada: "Situaciones nuevas (AG 6) que nacen de cambios socio-culturales y requieren una nueva Evangelización" (DP 366, 428, 433, 436, 438 etc.). Conviene recordar la amplia comprensión y el extraordinario desarrollo que en este documento se da a la misión evangelizadora de la Iglesia (DP 340-562).

Cabe otra pregunta: ¿Cuál es el contenido histórico, existencial y teológico de esta nueva Evangelización? El mismo Papa lo manifestaba en el ya citado discurso de Haití: "Una luz que podrá orientar la nueva evangelización deberá ser la del documento de Puebla, consagrado a este tema, en cuanto impregnado de la enseñanza del Vaticano II y coherente con el Evangelio" 5.

En el reciente Documento de Trabajo para Santo Domingo se pretende ofrecer el camino completo que ofrece las claves de la Nueva Evangelización: "América Latina va trazando su peregrinaje de fe en la escucha al espíritu que se dirige a todas las Iglesias. Desde la evangelización fundante entroncan hoy con los grandes acontecimientos eclesiales de nuestro siglo: Río, Medellín y Puebla. Cada uno puso un acento al anuncio del Evangelio y ofreció así su aporte original. (...) Junto a estos tres acentos sobresalen unas líneas comunes que configuran la trabazón interna de la historia de nuestras

5. Ecclesia 2119 (1983) 415. 
iglesias: la preocupación por la persona humana como hilo conductor, la evangelización como vocación irrenunciable de todo el pueblo de Dios, la liberación integral como expresión, reconciliación, lucha por la justicia y vivencia de la fraternidad" (DTST 305-307).

Con clarividencia el documento ha pretendido distinguir dos etapas: la de la evangelización fundante y la de la nueva evangelización. En el desarrollo de la segunda, como momentos privilegiados de su gestación ha marcado tres momentos: Río (1955), Medellín (1968) y Puebla (1979). Sin ellos no se puede comprender el denso contenido de la Nueva Evangelización de América Latina, que sigue abierta para dar respuesta a la coyuntura histórica que vive el continente (DTSD 308).

Creo que es una importante intuición el que el Documento haya conectado la etapa de la Nueva Evangelización con la de la evangelización fundante en América, ya que sirve para subrayar la originalidad y autoctonía en la que se desarrollan nuestras Iglesias. En efecto, prescindiendo de las abundantes sombras y nubarrones de la primera evangelización, sin embargo el acierto y la creatividad de los grandes misioneros, la dejó marcada con dos grandes objetivos: transmitir la fe y defender la causa de los aplastados promoviendo la justicia. Así lo subrayaba el Papa en su discurso de Santo Domingo en 1984 y añadía: "Con ello la Iglesia, frente al pecado de los hombres, incluso de sus hijos trató de poner entonces -como en las otras épocas- gracia de conversión, esperanza de salvación, solidaridad con el desamparado, esfuerzo de liberación integral" 6 .

Resumiendo: cuando Juan Pablo II establece sus primeros contactos con América Latina se encuentra con un proceso de renovación evangelizadora, original y autóctona, adaptado a las nuevas circunstancias, bien definido y que comienza a sugerir su propio nombre: la Nueva Evangelización. Como Vicario de Pedro y en función del ministerio dado por el Señor confirmó a sus hermanos en la fe (LC 22,32).

Ahora bien, dado que lo que hoy llamamos Nueva Evangelización es el resultado de un largo proceso, parece que la mejor manera para comprender su contenido real es seguir las distintas etapas, aunque sólo sea esquemáticamente, que lo han ido conformando.

\section{Hacia una nueva situación socio-cultural en América Latina}

En la década de los 40 se acelera el proceso de modernización industrial en los países más representativos de América Latina, bajo el signo predominante del desarrollismo liberal y económico. Sus consecuencias, en todos los

6. Ecclesia 2193 (1984) 1279. 
órdenes, iban a ser insospechadas, inaugurando una nueva época histórica, en la que se ha configurado la actual realidad del continente.

El fenómeno coincide con el final de la guerra mundial (1939-1945), cuyo resultado va a ser la constitución de dos imperios, que diplomáticamente se han dividido las zonas geográficas de influencia. Cada uno de ellos representa una orientación política y cultural marcadamente diferenciada. La paz firmada por ellos pronto se transforma en una peligrosa y prolongada guerra fría, que se va a hacer presente en casi todas las áreas del planeta y, muy especialmente, en América Latina.

En efecto, el terreno estaba preparado para ello. El modelo de desarrollo economicista, en la que quedaba situada la modernización industrial, implicaba gravísimos costos humanos y sociales para las inmensas mayorías populares del continente, como enseguida comenzó a acusarse. Pronto las naciones comenzaron a militarizarse y progresivamente fueron entrando en la que Argentina ha calificado como guerras sucias: Ejércitos, orientados en su praxis por la ideología de la Seguridad Nacional, frente a guerrillas populares. Fue un fenómeno de violencia, que se incrementó acusadamente después del triunfo cubano en 1959.

Pero, prescindiendo de otros aspectos y de ideologizaciones coyunturales, a mi juicio, tres nuevos valores emergieron en las que Oscar Lewis ha llamado las culturas de la pobreza 7 , con amplias repercusiones en todos los ámbitos latinoamericanos. Sobresale, en primer lugar, una maduración de la conciencia colectiva popular, directamente conectada con la dignidad humana, base sobre la que se sustentan los derechos fundamentales de todo hombre y de todo pueblo. Segundo, una valoración negativa de todo tipo de dependencias impuestas que sean generadoras de situaciones inhumanas e injustas. Tercero, un descubrimiento del valor, del derecho y de la posibilidad de la liberación en orden al desarrollo humano integral. De hecho, pueblo -como sinónimo de pobres y oprimidos, cubriendo una extensa y diversificada gama-, dependencia y liberación forman una trilogía verbal, que, durante estos años, se ha incorporado vigorosa y significativamente al lenguaje $\mathrm{y}$, consiguientemente, a las culturas latinoamericanas.

\section{La Conferencia Episcopal de Río de Janeiro (1955)}

En plena gestación de este nuevo contexto social y cultural, en 1955, bajo el impulso de Pío XII, se reúne en Río de Janeiro la primera conferen-

7. O. LEwIS, "Five families. Mexican Case Stuides in the Culture of Poverty", Nueva York 1959. A. González Dorado, "Las culturas de la pobreza en América Latina", en "Hacia la Cuarta Conferencia”, Bogotá 1992, pp. 331-347. 
cia del episcopado Latinoamericano ${ }^{8}$. Desde una perspectiva documental y oficial, la podemos considerar como punto de partida y primera etapa de la Nueva Evangelización.

La Conferencia se desenvuelve en un ambiente de preocupación pastoral. Lógicamente se encuentra condicionada por dos limitaciones: la acelerada novedad de los nuevos acontecimientos políticos y sociales, y la situación preconciliar, en la que se encontraba toda la Iglesia.

Es importante el subrayar el amplio marco de estudios sobre la realidad latinoamericana, dividido en diez densas áreas, con el que se abre la Conferencia, en los que germinalmente van a aparecer ya casi todos los problemas que durante estos años han constituido la preocupación constante de nuestras Iglesias.

Releyendo sus conclusiones, desde nuestra perspectiva actual, aparecen extraordinariamente significativas y proféticas, impulsoras de un nuevo movimiento evangelizador para una nueva situación emergente.

Se proponen dos grandes objetivos: una evangelización intensa y renovada, en orden a la defensa y formación de la fe, y una colaboración en la solución de los problemas sociales que afectan al hombre latinoamericano, especialmente en los campos del salario, la vivienda y el desempleo, abogando por una justa solución de ellos.

Es de resaltar que, entre otros aspectos, para la renovación de la evangelización insiste en la lectura de las Sagradas Escrituras, en el fomento de las ediciones populares de la Palabra de Dios, en la celebración del día nacional de la Biblia y en la organización de cursos bíblicos. Curiosamente, frente al proselitismo protestante que comenzaba a desarrollarse durante estos años ${ }^{9}$, recomienda la labor de acercamiento a los hermanos separados de la Iglesia, por medio de la amistad y del apostolado.

El segundo objetivo es la aportación de la Iglesias a los nuevos problemas sociales que estaban surgiendo o de los que comenzaba a concientizarse. Sobresalen dos ámbitos de preocupación: la real situación social que comen-

8. J. Botero, "El CELAM. Apuntes para una crónica de sus 25 años", Eds. CELAM, Medellín 1982, pp. 9-82.

9. "La agresiva propaganda protestante y de los nuevos movimientos religiosos, empezó a incidir con fuerza y a provocar tensiones y deterioro, incluso en la religiosidad popular, sobre todo a partir de los Congresos Protestantes de Montevideo (1915) y de La Habana (1292) considerando a América Latina como territorio de misión. Cuando los misioneros estadounidenses fueron expulsados de China (1927, 1934 y 1949), muchos se replegaron a nuestro continente de donde comenzaron a conseguir adeptos, sobre todo -como lo dijeron en 1956 los obispos centroamericanos- a causa de la ignorancia religiosa de los pueblos" (DTSD 109). Actualmente algunas de las denominadas Iglesias Electrónicas hablan de la liberación del pueblo latinoamericano del catolicismo". 
zaba a agravarse en amplios sectores populares, y la constante y eficaz penetración del comunismo. Ya en este ámbito se focalizan y destacan los sectores más afectados: campesinos, negros e indios. Con relación a estos últimos se sugería la creación de un Instituto Indigenista y etnológico en América Latina y se condenaba la discriminación racial y el abuso de los bienes y de las personas de los indígenas. El problema de las nuevas poblaciones urbanas se comenzará a subrayar en la V Asamblea Ordinaria del CELAM celebrada en Buenos Aires en 1960, destacando el aumento de barrios de miseria.

Para enfrentar estas dos grandes misiones la Conferencia proponía dos medios básicos y dinamizadores: promoción y formación de nuevos agentes cristianos, e integración interna de las Iglesias latinoamericanas.

Con relación al primer medio, lógicamente, se subrayaba el sector de los sacerdotes y de los religiosos. Pero novedosamente se subrayaba la importancia de los laicos como colaboradores de los sacerdotes, en una situación de clero escaso, como misioneros de conquista, y como sujetos específicos de vocaciones sociales y cívicas.

Pero el medio fundamental para desarrollar este proyecto era la integración colegial de las Iglesias latinoamericanas. Así lo manifestó textualmente el Cardenal Piazza, enviado especial por Pío XII: "No podrá hacerse frente a los problemas de la Iglesia Latinoamericana aisladamente". Propuesta que fue rápidamente recibida por Msr. Manuel Larraín con una afirmación profética, aunque no exenta de un cierto optimismo: "Sólamente una América Latina estrechamente unida, no sólo en la fe y en la caridad, como ya está, sino más que todo en la acción, podrá dar a la Iglesia la respuesta de esperanza redentora que de ella se espera". La propuesta de unas Iglesias operativamente integradas abría el horizonte de la necesidad de promover unas naciones y una América Latina internamente integradas y solidarias.

La respuesta a esta urgencia fue la creación inmediata del CELAM, y la fundación de la CLAR y de la OSLAM en 1958.

\section{Hacia el Concilio Vaticano II}

A partir de 1956 el CELAM institucionaliza sus asambleas anuales. Son años, en los que se van agravando los problemas humanos y sociales de la nueva América Latina emergente, generalizándose en todas naciones una situación revolucionaria o prerrevolucionaria que, en el contexto de la guerra fría, tiende a buscar soluciones por el camino rápido de la violencia, que pronto se encuentra con la contestación de una inhumana y organizada represión.

Las asambleas se constituyen en momentos privilegiados, en los que la Iglesia sigue los acontecimientos del continente, interioriza y clarifica sus 
problemas cada vez más graves y que inciden en la propia comunidad eclesial, y en los que progresivamente va orientando el ejercicio de su misión en una situación tan urgente y novedosa. Baste recordar la IV Asamblea celebrada en Fómeque (Colombia) el año 1959, que dará origen a la declaración "La Iglesia ante los problemas económico-sociales de América Latina", y la de México en 1961, con la célebre y lúcida intervención de Msr. Hélder Cámara.

Ya se encontraba en marcha el movimiento de una nueva evangelización de y para América Latina en su nueva situación socio-cultural. Sólo necesitaba un nuevo contexto teológico y eclesial para confirmarse y justificarse más lúcidamente. Y entonces aconteció el Concilio Vaticano II.

No es el momento de enfatizar ni de desarrollar el profundo cambio de mentalidad eclesial que el Concilio aportaba ${ }^{10}$, ni la novedad de las orientaciones pastorales que ofrecía en todos los campos.

Probablemente los documentos que más han influido en América Latina han sido Lumen Gentium, Gaudium et spes y el decreto Ad gentes.

En ese momento iban a tener especial incidencia dos intervenciones de Pablo VI: su exhortación apostólica a los Obispos latinoamericanos pronunciada el 24 de noviembre de 1965, y su encíclica Populorum progressio.

\section{Medellín y Melgar (1968)}

Llegamos a la segunda etapa, probablemente la más decisiva, de la configuración autóctona de la nueva evangelización en América Latina.

El título de la Conferencia de Medellín ya es significativo: "Presencia de la Iglesia en la actual transformación de América Latina".

Con plena lucidez se decía en el Documento de Pastoral Popular: "Hay un proceso de transformación cultural y religiosa. La evangelización del continente experimenta serias dificultades, que se ven agravadas por la explosión demográfica, las migraciones internas, los cambios socio-culturales, la escasez de personal apostólico y la deficiente adaptación de las estructuras eclesiales" (I,1). En vísperas de las asambleas decía Msr. Pablo Muñoz Vega: "Basta dirigir una mirada a la situación actual de América Latina y ver los problemas que la agitan, problemas sociales y económicos, el problema de su fe, el demográfico, el educativo etc., para darnos cuenta de que vivimos en la coyuntura histórica más grave de nuestro continente" 11.

10. A. Gonzalez Dorado, "La Nueva Evangelización y la mentalidad eclesial", en Pastoral Misionera 177 (1991) 47-63.

11. J. Botero, "El CELAM" (o.c,) p. 132. 
Las líneas maestras del proyecto elaborado por la Conferencia fueron muy claras, y siendo suficientemente conocidas bastará un somero recuerdo de ellas.

Primero, opción preferencial y solidaria con los pobres. "Esto ha de concentrarse en la denuncia de la injusticia y la opresión, en la lucha cristiana contra la intolerable situación que soporta con frecuencia el pobre, en la disposición al diálogo con los grupos responsables de esa situación para hacerles comprender sus obligaciones" (Doc. 14, III, 9-10). Significativamente el Papa había afirmado que "los pobres son sacramento de Cristo" 12.

Segundo, promocionar una evangelización adaptada y promover la maduración en la fe de los pueblos y sus élites, a través de la catequesis y la liturgia.

Tercero, impulsar una liberación integral que atienda simultáneamente a la conversión interior, a la transformación de las estructuras (Doc. Justicia 3-4), y a la humanización de las culturas (Doc. Educación 8-9).

Cuarto, en orden a conseguir dichos objetos se establecía la necesidad de promover un nuevo modelo de Iglesia que se delineaba con los siguientes rasgos: "Que se presente cada vez más nítido en Latinoamérica el rostro de una Iglesia auténticamente pobre, misionera y pascual, desligada de todo poder temporal y audazmente comprometida en la liberación de todo el hombre y de todos los hombres" (Doc. Juventud 15 a.).

La autoctonía y originalidad de este proyecto aparecen con mayor claridad cuando se las compara con las preocupaciones que se manifestaban en otros continentes. En efecto, en estos mismos años, en otras zonas se desarrollaban la Teología de la Muerte de Dios, la Teología del Ocio y la Eclesiología de la Diáspora. Mientras tanto, en América Latina, la Iglesia ofrecía las bases para una Teología del Dios Liberador, para una Teología de los Pobres y los Oprimidos, y para una Eclesiología de la Liberación.

Es evidente que, con responsabilidad y entusiasmo, la Iglesia había logrado encarnarse en la nueva situación histórica de continente y sintonizar con la nueva cultura emergente. Por eso Medellín fue un Pentecostés para la Iglesia y una Buena Noticia para los pobres. Resulta normal que en el mismo documento comenzara a labrarse la expresión de una Nueva Evangelización.

En el mismo año de 1968, se produce otro acontecimiento de extraordinaria importancia, aunque hemos conocido en Europa: el encuentro de Melgar. En el ambiente generalizado de Medellín y a la luz de los documentos 
del Vaticano II, se afronta el tema de las misiones y, más concretamente, el de la situación y comprensión de las comunidades aborígenes, que totalizan una población superior a los 40.000.000, y que forman el grupo de "los más pobres entre los pobres" (DP 34).

Es un momento en el que, en medio del generalizado proceso de maduración y desarrollo de la conciencia popular, los aborígenes comienzan a hacerse presentes en el foro público exigiendo una revisión crítica de los últimos quinientos años de su historia deformada y encubierta, afirmando su dignidad y originalidad, cuestionando la orientación de las políticas indigenistas, y reclamando el reconocimiento operativo de sus inalienables derechos humanos. Hablan de su resistencia mantenida durante medio milenio, y denuncian la situación de marginación, explotación e integracionismo etnocida al que se encuentran sometidos en todos los países. Su crítica alcanza también a la Iglesia y, especialmente, a la historia y métodos de sus misiones.

La asamblea de Melgar logró interiorizar esta nueva situación de las comunidades aborígenes, y comenzó a roturar rutas para una nueva evangelización liberadora, que se ha ido clarificando en los años posteriores.

\section{Se inicia la marcha de la Iglesia de los mártires}

Pocas fechas antes del inicio de la Conferencia de Medellín, el Cardenal Juan Landázuri decía: "La Conferencia ha de ser un comienzo. Se ha de iniciar en ella una nueva etapa para la Iglesia de América Latina... Este mundo nuevo, pujante, ansioso de justicia, espera nuestra palabra, pero más aún, aguarda nuestra acción" ${ }^{13}$. Y ciertamente, con fuerza y creatividad pentecostales Medellín fue el motor impulsor que puso a todas las Iglesias de América Latina en una marcha nueva.

En efecto, las Conferencias Episcopales se consolidaron, asumiendo muchas de ellas una función profética en sus propios países. Se comenzaron a multiplicar las comunidades eclesiales de base. Muchos religiosos y religiosas se orientaron hacia el apostolado de inserción. Se incrementaron las vocaciones sacerdotales y laicales, fuertemente marcadas por un compromiso social. Surgió en Chile el movimiento de cristianos por el socialismo. La reflexión teológica, puesta al servicio de las nuevas orientaciones, originó la Teología de la Liberación, que casi simultáneamente se hace presente en muchas naciones. Se profundiza sobre la religiosidad popular en orden a un mayor conocimiento del pueblo y para obtener una mayor clarificación sobre ella desde el pueblo, que conducirá a cualificarla fundamentalmente

13. J. BOTERo, "EI CELAM" (o.c., ) p. 131-132. 
como catolicismo popular. Se inicia el reajuste misionero y pastoral en las comunidades aborígenes, etc. etc. etc.

Pero todo este complejo conjunto de fenómenos se van a encontrar situados en la década de los 70 , probablemente la más conflictiva social y políticamente de la nueva época de América Latina. Durante este período se multiplican las dictaduras militares y se endurece el sistema institucionalizado de la represión. Serán largos años de apresamientos masivos, de expulsiones, torturas, desaparecidos, asesinados, sin el menor respeto a los derechos humanos más elementales. La Iglesia ha entrado en sospecha y es colocada en el punto de mira de gobiernos que oficialmente se proclaman cristianos. Así se inicia una interminable lista de mártires y confesores entre los que abundan catequistas, responsables de la palabra, religiosos y religiosas, sacerdotes e incluso obispos, como Mrs. Oscar Romero y Mrs. Angelelli.

La situación externa del conflicto rápidamente se interiorizó en la propia Iglesia, que se encontraba iniciando una nueva andadura a partir de Medellín. Es evidente que la expansión de la vida siempre es mucho más compleja y diversificada que la nitidez y la simplicidad de un documento.

En tales circunstancias, algunos llegaron incluso a cuestionar a Medellín y consiguientemente la nueva evangelización liberadora. Creo que la mejor respuesta fue en 1975 la exhortación apostólica Evangelii Nuntiandi de Pablo VI, la carta magna de la evangelización.

No obstante ser un documento dirigido a toda la Iglesia universal, son evidentes las resonancias latinoamericanas que en él se advierten. Se despliega doctrinalmente casi como una gran fundamentación teológica de Medellín, abordando las más candentes dimensiones de la misión evangelizadora de la Iglesia, y procurando dar ajustadas orientaciones en cada una de ellas. Evangelii Nuntiandi no sólo es la carta magna de la misión evangelizadora, sino también la de la nueva evangelización latinoamericana.

\section{La Conferencia de Puebla de los Angeles (1979)}

La Conferencia de Puebla la podemos considerar como la tercera etapa del despliegue de la nueva evangelización en América Latina. Su título hace clara referencia a la Evangelii Nuntiandi: "La evangelización en el presente y en el futuro de América Latina".

En la lectura del documento es fácil descubrir, para los testigos directos de la época, que el nuevo movimiento evangelizador ya no se reduce a un proyecto, sino que ha comenzado a ser historia en la vida de la Iglesia. Se hacen constantes referencias a nuevos estilos testimoniales de vida y a nuevas realidades eclesiales, inéditas antes de 1955. 
La visión pastoral de la realidad latinoamericana, que se presenta en la primera parte del documento (DP 1-161), muestra la dramática e incluso trágica situación a la que se encontraba sometido el continente durante ese decenio. Es impresionante y significativo el siguiente texto: "Desde el seno de los diversos países del continente está subiendo hasta el cielo un clamor cada vez más tumultuoso e impresionante. Es el grito de un pueblo que sufre y que demanda justicia, libertad, respeto a los derechos fundamentales del hombre y de los pueblos" (DP 87). Y añadía significativamente: "La Conferencia de Medellín apuntaba ya, hace poco más de diez años, la comprobación de este hecho: Un sordo clamor brota de millones de hombres, pidiendo a sus pastores una liberación que no les llega de ninguna parte. El clamor pudo haber parecido sordo en ese entonces. Ahora es claro, creciente, impetuoso y, en ocasiones, amenazante" (DP. 88-89).

Tampoco se ocultaban los conflictos surgidos al interior de la propia Iglesia: "Las dolorosas tensiones doctrinales, pastorales y sicológicas entre agentes pastorales de distintas tendencias, si bien subsisten aún, van siendo superadas gradualmente, mediante la práctica del diálogo abierto y constructivo" (DP 102).

Dentro de este contexto y de esta historia sobresalieron tres preocupaciones en la Conferencia de Puebla: confirmar y ratificar las orientaciones dadas en Medellín, fundamentar teológicamente la compleja misión de la Iglesia, y profundizar su nuevo modelo en una dinámica de comunión y participación.

Medellín queda subrayado como uno de los grandes momentos de la evangelización en América Latina. Expresamente se afirmaba: "Sobre todo a partir de Medellín, con clara conciencia de su misión, abierta lealmente al diálogo, la Iglesia escruta los signos de los tiempos y está generosamente dispuesta a evangelizar, para contribuir a la construcción de una sociedad, más justa y fraterna, clamorosa exigencia de nuestros pueblos. (...). Así, en este vasto movimiento renovador que inaugura una nueva época, en medio de los recientes desafíos, los pastores aceptamos la secular tradición episcopal del continente y nos preparamos para llevar, con esperanza y fortaleza, el mensaje de salvación del Evangelio, preferentemente a los más pobres y olvidados" (DP 12). Aceptar Medellín suponía mantener viva su original opción preferencial por los pobres (DP 1134-1165), y su comprensión evangelizadora como un proceso dinámico de liberación integral (DP 480).

Reafirmando a Medellín y reafirmándose en él, Puebla busca, en segundo lugar, un punto de referencia teológico capaz de unificar los diferentes compromisos de la Iglesia, de orientar sus análisis de la realidad envolvente, de juzgar y discernir sus aciertos y desaciertos en el caminar. Recientemente Pablo VI había publicado la Evangelii Nuntiandi, documento al que recurre 
la Conferencia, encontrando la clave en la misión evangelizadora. En su núcleo emergen, con una luz nueva, la verdad de Jesucristo (DP 170-219), la verdad de la Iglesia (DP 220-303), y la verdad sobre el hombre y la dignidad humana (DP 304-339). En su proyección histórica, se recogen y subrayan las grandes preocupaciones y los graves compromisos de las Iglesias latinoamericanas: Evangelización y proclamación del mensaje, evangelización y cultura, evangelización impulsora de liberación y de promoción humana, evangelización ante las ideologías y la política (DP 340-562). El documento claramente manifestaba que "nuestra evangelización está marcada por algunas preocupaciones particulares y acentos más fuertes: la redención integral de las culturas, antiguas y nuevas de nuestro continente, teniendo en cuenta la religiosidad de nuestros pueblos; la promoción de la dignidad del hombre y la liberación de todas las servidumbres e idolatría: la necesidad de hacer penetrar el vigor del Evangelio hasta los centros de decisión, las fuentes inspiradoras y los modelos de la vida social y política" (DP 342-345).

Por último, dadas las graves circunstancias en las que se encontraba el continente, y clarificada la única y compleja misión evangelizadora, Puebla, dados los conflictos internos surgidos durante los últimos años, impulsa a todos a promover una Iglesia de comunión y participación (DP 211-218; 563-1127).

Mas aún, dada la importancia del testimonio, el documento subraya la urgencia de promover la comunión y la participación al interior de la Iglesia, para que ella a su vez pueda impulsarla en todo el continente. Desde esta perspectiva se complementa el modelo de Iglesia propuesto por Medellín: "La Iglesia evangeliza, en primer lugar, mediante el testimonio global de su vida. (...) La pedagogía de la Encarnación nos enseña que los hombres necesitan modelos preclaros que los guíen. América Latina también necesita tales modelos. Cada comunidad eclesial debería esforzarse por constituir para el continente un ejemplo de modo de convivencia donde logren aunarse la libertad y la solidaridad. Donde la autoridad se ejerza con el espíritu del Buen Pastor. Donde se viva una actitud diferente frente a la riqueza. Donde se ensayen formas de organización y estructuras de participación, capaces de abrir camino hacia un tipo más humano de sociedad. Y sobre todo, donde inequívocamente se manifieste que, sin una radical comunión con Dios en Jesucristo, cualquier otra forma de comunión puramente humana resulte a la postre incapaz de sustentarse y termina fatalmente volviéndose contra el mismo hombre" (DP 272-273).

Curiosamente, a todo el proceso autóctono y evangelizador que la Iglesia venía desarrollando en América Latina, en su nueva situación de cambios socioculturales, y que con decisión pretende proseguir, Puebla lo llama "una nueva Evangelización" (DP 366). Más aún, se tiene una conciencia de que dicha evangelización puede ofrecer algo importante al resto de las Iglesias: "Nuestras Igle- 
sias pueden ofrecer (a las otras) algo original e importante: su sentido de la salvación y de la liberación, la riqueza de su religiosidad popular, la experiencia de las comunidades eclesiales de base, la floración de sus ministerios, su esperanza y la alegría de su fe. Hemos realizado ya esfuerzos misioneros que pueden profundizarse y deben extenderse" (DP 368). Se trata de una aportación sellada con el más radical de los testimonios. Baste recordar un sólo texto de los varios ofrecidos por Puebla: "Es admirable y alentador comprobar el espíritu de sacrificio y abnegación con que muchos pastores ejercen su ministerio en servicio del Evangelio, sea en la predicación, sea en la celebración de los sacramentos o en la defensa de la dignidad humana, afrontando la soledad, el aislamiento, la incomprensión y, a veces, la persecución y la muerte" (DP 668).

Esta es la Nueva Evangelización, con la que se encontró Juan Pablo II en Puebla, la que confirmó y proclamó en Haití, y la que ha seguido decididamente impulsando durante estos años.

\section{Hacia Santo Domingo 1992: Cuarta etapa de la Nueva Evangeli- ZACION}

En estas fechas de finales del mes de agosto, nos encontramos en las cercanías de la celebración de la IV Conferencia del Episcopado Latinoamericano, que se inaugurará el 12 de octubre en Santo Domingo.

Sobre ella hay abiertas muchas cuestiones y se manifiestan grandes preocupaciones. En el fondo todas ellas se reducen a una pregunta fundamental: ¿La Conferencia seguirá impulsando y abriendo nuevos caminos a la Nueva Evangelización promovida por Río, Medellín y Puebla, o detendrá su dinamismo sometiéndolo a un proceso de involución?

No soy profeta ni poseo una mágica bola de cristal para descubrir el futuro, aunque éste se encuentre a noventa días vista. Por eso, sólo me voy a detener a examinar el contenido de los principales documentos que, sin duda, serán tenidos en cuenta por la Conferencia, o que han sido elaborados como material de apoyo para la misma. Principalmente en estos últimos se expresa lo que se espera de ella.

\section{Documentos más importantes}

Entre los documentos, que sin duda serán tenidos en cuenta, destacan los de Juan Pablo II. Entre ellos sobresalen Laborem exercens, Sollicitudo rei socialis, Christifideles laici, Redemptoris missio y Centessimus annus. A estos hay que añadir sus múltiples exposiciones y orientaciones sobre la Nueva Evangelización en América Latina, que ha ido desarrollando en sus diferentes viajes al continente. 
Como documento directamente preparado para la Conferencia, sin duda el más importante es el recientemente publicado con el modesto título de Documento de Trabajo ${ }^{14}$, en cuya introducción reeoge el discurso del Santo Padre a la II Asamblea Plenaria de la Pontificia Comisión para América Latina, pronunciado el 14 de junio de 1991. Este documento viene acompañado por otros diez documentos auxiliares, que ayudan a clarificar su lectura ${ }^{15}$.

Creo que también son importantes otras aportaciones que se han elaborado durante la época de preparación. Entre ellas sobresalen "Nueva Evangelización: Génesis y líneas de un proyecto misionero" ${ }^{16}$, Hacia la Cuarta Conferencia" 17, "Constructores del amor en América Latina" ${ }^{18}$, y "Doctrina social de la Iglesia en América Latina" ${ }^{19}$.

La CLAR, dentro de su situación todavía difícil, en su XXV Junta Directiva, celebrada en San José de Costa Rica del 1 al 8 de junio de 1992, también ha elaborado un "Subsidio para los Delegados de la Vida Religiosa en Santo Domingo". Sólo con 23 páginas fotocopiadas. Pero el documento es claro y sugerente.

Mis reflexiones, sin olvidar los otros documentos, se centran preferentemente en el "Documento de Trabajo", cuya elaboración quedó terminada el 19 de abril, y cuya primera edición quedó impresa en junio de 1992. Será el punto de partida para la IV Conferencia.

\section{América Latina ante la nueva situación internacional}

En el documento elaborado por la CLAR acertadamente se analiza y pondera el "impacto del nuevo orden internacional en América Latina" ${ }^{20}$.

14. "Nueva evangelización, promoción humana, cultura cristiana", Eds. CELAM, Bogotá 1992. Citamos este libro con la sigla DTSD.

15. Estos documentos auxiliares tienen los siguientes títulos: "Memoria indígena", "Glosás y comentarios", "Jesucristo ayer, hoy y siempre", "Hacia la cuarta conferencia", "Aportes de las Conferencias Episcopales a la IV Conferencia", "Evangelización, teología y pastoral", "El hombre a la luz del misterio de Cristo en Juan Pablo II", "Indiferentismo y sincretismo", "Doctrina social de la Iglesia en América Latina", y "Juan Pablo II a la Iglesia en América Latina".

16. AA.VV, "Nueva Evangelización: Génesis y líneas de un proyecto misionero", Eds. CELAM, Bogotá 1990, pp. 300.

17. AA.VV., "Hacia la Cuarta Conferencia", Eds. CELAM, Bogotá 1992, pp. 523. pp. 794.

18. AA.VV., "Constructores del amor en América Latina", Eds. CELAM, Bogotá 1992,

19. AA.VV., "Doctrina social de la Iglesia en América Latina", Eds. CELAM, Bogotá 1992, pp. 934.

20. Confederacion Latinoamericana de Religiosos (CLAR), "Subsidio para los delegados y delegadas de la vida religiosa en Santo Domingo", Fotocopiado, San José de Costa Rica 1992, pp. 12-18. 
En efecto, durante la década de los años 80 se inició un progresivo debilitamiento de la guerra fría, que culminó con la caída del muro de Berlín y el derrumbamiento de la Unión Soviética y los países del este europeo, lo que ha constituido un revulsivo de primer orden. "El triunfo del primer mundo se ha traducido apocalípticamente como el fin de la historia (Fukuyama) y el Tercer Mundo se ha borrado sencillamente del mápa al desaparecer el referente -segundo mundo- que le servía de sustentación. La descripción resultante de este enfoque es una falsificación de la realidad de una gravedad tan palmaria y de tan peligrosas consecuencias que es ineluctable llamar la atención sobre ella" ${ }^{21}$.

De hecho, nos encontramos ante un triunfo y generalización de un neoliberalismo pragmático (DTSD 147), que aceleradamente se impone desde el Hemisferio Norte como un nuevo y único modelo de imperialismo económico. Teóricamente el Tercer Mundo ha desaparecido, pero no los gravísimos problemas de sus naciones, como ya lo ha comenzado a mostrar el surgimiento del fundamentalismo islámico, la primera contestación de las naciones en vías de desarrollo al nuevo orden internacional.

El impacto causado en América Latina por esta nueva situación internacional ha sido inmediato, como repetidamente aparece en el Documento de Trabajo del CELAM.

Se reconoce que "la década del ochenta se caracterizó por el paso de los regímenes militares a un sistema de gobierno democrático. Este paso ha significado el ejercicio de la libertad cívica en contraste con la inseguridad que se experimentaba en los regímenes anteriores. Sin embargo, también existe un ambiente de desencanto y frustración debido a la lucha partidista signada por el sectarismo, la ambición personal, el clientelismo partidista y el no cumplimiento de las promesas electorales" (DTSD 150). Y añade: "Un sistema democrático representativo mediante el voto electoral pero que aún no ha logrado implantar la participación real de la ciudadanía; la incapacidad del Estado de responder oportunamente a las demandas sociales; la progresiva pérdida de confianza en los políticos; la corrupción; y la ineficiente burocracia de la administración pública, reducen la puesta en práctica del sistema democrático a una mera formalidad que no beneficia a las grandes mayorías de nuestras sociedades. Aún más, el desencanto frente a los gobiernos democráticos aumenta la violencia terrorista. La evidente debilidad y corrupción presentes en las instituciones públicas en la mayoría de nuestros 
países genera altas cuotas de violencia en la medida que se pierde confianza en ellas y se actúa al margen de las mismas" (DTSD 154).

Desde el punto de vista económico a los ochenta se los comienza a designar como la década perdida, "debido al retroceso en el poder adquisitivo que han experimentado nuestros pueblos, con la consiguiente degradación de sus niveles de vida. El peso de la deuda externa, la caída del ingreso medio per cápita en estos últimos trece años, el flagelo de la inflación, la baja inversión tanto nacional como extranjera, la intervención de los sistemas financieros para evitar su quiebra, la dramática reducción de los salarios, el aumento real del sub y desempleo, las situaciones de miseria de jubilados y pensionados, y la impotencia del Estado para enfrentar los enormes problemas sociales, constituyen realidades trágicas que justifican el adjetivo aplicado a los ochenta y que implican no tanto cifras estadísticas cuanto situaciones dolorosas a tantos hombres, mujeres, ancianos, jóvenes y niños de nuestros pueblos" (DTSD 129). Simultáneamente se constata que "dentro de nuestros países, se da una concentración de riqueza en las manos de unos pocos, y una masiva fuga de capitales que no redunda en beneficio de la gran mayoría empobrecida. Ello constituye una grave falta de solidaridad para con quienes han hecho posible la acumulación de esos capitales. Lamentablemente, la brecha entre los países ricos y pobres, y entre ricos y pobres en el interior de los mismos países, sigue siendo una realidad que contradice la fraternidad que debería imperar entre nosotros" (DTSD 133).

Por otra parte, la situación no parece transitoria sino que tenderá a agravarse. Es conocido que las recetas del nuevo sistema, incluso en países del primer mundo, han comenzado a generar gravísimos problemas sociales. $\mathrm{El}$ incremento del desempleo, desde Japón a Estados Unidos ha hecho emerger un mundo de marginados, que se sumergen en la drogadicción, el alcoholismo y la desesperación personal, incrementando la inseguridad ciudadana y estallidos de rebeldías incontroladas como las que hemos visto recientemente por la televisión. Reflexionando sobre América Latina, el Documento de Trabajo anota que "alguno ya hablan de la superación del concepto de dependencia por uno de presidencia en lo que se refiere al papel de nuestro continente en el futuro" (DTSD 146).

Dentro de este nuevo ambiente, también se siente especialmente afectada la comunidad católica en su fe y en su ética. Por una parte, favorece a la agresiva propaganda de algunas designaciones protestantes y especialmente de los nuevos movimientos religiosos (DTSD 109), de los que algunos, especialmente las iglesias electrónicas, orientan su campaña como una liberación popular del catolicismo. Por otra parte, la masiva penetración de la modernidad no sólo ha aportado determinados valores positivos de un nuevo huma- 
nismo, sino también ha contribuido "a la marginación social de la religión y de la ética. La mayor importancia dada a la decisión individual, al pluralismo y a la libertad de conciencia, ha ayudado a que se asuman las responsabilidades con mayor serenidad y convicción, pero ha fragmentado la visión cristiana global y el seguimiento de las normas objetivas morales que sostiene la Iglesia católica" (DTSD 110).

3. Confirmación de Medellín y de la opción preferencial por los pobres y los jóvenes

El Documento de Trabajo, consciente de la actual y nueva situación del continente, propone explícitamente a la Conferencia la confirmación de Medellín y del proceso evangelizador seguido por la Iglesia desde 1955: "Desde la evangelización fundante, entronca hoy con los grandes acontecimientos eclesiales de nuestro siglo: Río, Medellín y Puebla. Cada uno puso un acento al anuncio del Evangelio y ofreció así su aporte original: agentes evangelizadores mejor preparados; la difícil situación de pobreza y de injusticia de los hombres y mujeres de América Latina; la comunión y participación como condición de credibilidad en la proclamación del Reino de Dios" (DTSD 306). Y añade: "Junto a estos tres acentos sobresalen unas líneas comunes que configuran la trabazón interna de nuestras iglesias: la preocupación por la persona humana como hilo conductor, la evangelización como vocación irrenunciable de todo el pueblo de Dios, la liberación integral como expresión de conversión, reconciliación, lucha por la justicia y vivencia de la fraternidad" (DTSD 308). Y termina diciendo: "Santo Domingo se dispone a retomar aquellas expectativas para traducirlas en proyectos nuevos, capaces de dar respuesta a la nueva coyuntura histórica que vive el continente" (DTSD 308).

Se proclama la vigencia de la opción por los pobres repetidamente, desarrollando que "esto implicará : solidarizarnos evangélicamente con los más débiles y pobres de América Latina, comprometiéndonos con eficacia para que recuperen su voz, su sitio y sus derechos. Crear iniciativas que secunden sus luchas por la justicia como condición de dignidad. Los pobres son protagonistas de evangelización al mismo tiempo que destinatarios" (DTSD 623).

Junto a los rostros de la pobreza descritos dramáticamente por Puebla (DP 31-41), añade otros nuevos que han ido surgiendo durantes estos años: "En el umbral del tercer milenio encontramos los rostros desfigurados por el hombre, consecuencia de la inflación, de la deuda externa y de las injusticias sociales; los rostros desilusionados por los políticos, que prometen pero no 
cumplen; los rostros humillados a causa de su propia cultura que no es respetada y es incluso desprećiada; los rostros aterrorizados por la violencia diaria e indiscriminada; los rostros angustiados de los menores abandonados que caminan por nuestras calles y duermen bajo nuestros puentes; los rostros sufridos de las mujeres humilladas y postergadas; los rostros cansados de los inmigrantes que no encuentran digna acogida; los rostros envejecidos por el tiempo y el trabajo de los que no tienen lo mínimo para sobrevivir dignamente" (DTSD 163).

Dentro de esta opción se destacan muy especialmente los pueblos que se integran en las culturas indígenas y afroamericanas (DTSD 281-282; 677684), los campesinos (DTSD 134), y los hacinados en las ciudades padeciendo "marginación, contaminación, desempleo, violencia, amoralismo, etc." (DTSD 283).

Opción por los pobres y opción por los jóvenes quedaron marcadas en Medellín y fueron asumidas por Puebla. Con relación a la segunda el Documento de Trabajo indica que "es particularmente urgente volver a esta opción que tiene plena vigencia entre nosotros. Razones de índole demográfica (población mayoritaria), social (víctimas de la sociedad de los adultos), cultural (impactos negativos en su sentido de la vida) y pastoral (atención insuficiente), nos aconsejan reafirmar esta opción dentro de la nueva evangelización. La mayoría de jóvenes latinoamericanos son pobres. Consecuencia de ellas son: asumir lealmente la realidad de los jóvenes, partiendo de su cultura que es, sobre todo, la cultura moderna; presentar alternativas para sus grandes interrogantes y conflictos; crear espacios para que ejerciten su protagonismo en la Iglesia; vincular la pastoral juvenil a la pastoral vocacional" (DTSD 625-626).

Hoy se pretende explicitar una tercera opción: la opción por la persona humana en la sociedad nacional e internacional. "Esta opción se centra en la defensa de la dignidad de la persona humana y en la promoción de la justicia. (...) Es necesario actualizar operativamente esta opción para mantener sin equívocos a la persona humana como el valor superior de la creación: la persona en su dimensión individual, comunitaria y social; en su carácter transcendente e inmanente; en su condición de una nacionalidad, de una minoría o de la comunidad internacional. Todo hombre y toda mujer en cada circunstancia de su vida, es la única criatura que Dios ha querido por sí misma y sobre la cual tiene su proyecto de salvación" (DTSD 633-634).

\section{Los tres grandes objetivos de la Nueva Evangelización}

Supuestas la continuidad histórica del nuevo movimiento evangelizador de la Iglesiá en América Latina, y la actual situación del continente en el nuevo con- 
texto mundial, el Documento de Trabajo, siguiendo las orientaciones dadas por Juan Pablo II, establece tres grandes objetivos para la nueva etapa de la Nueva Evangelización en el continente ${ }^{22}$. Expresamente afirma que pretende evitar una evangelización reduccionista, "a fin de llegar a proclamarla integralmente, sin sacrificar ninguno de sus valores, elementos o aspectos esenciales" (DTSD 455).

Estos objetivos son: anunciar el Evangelio, defender a la persona humana y la conversión radical del corazón al interior de las culturas (DTSD 309).

El primer objetivo es la clara proclamación de Jesucristo y de su mensaje: “... toda evangelización, antigua o nueva, ha de incluir en la sustancia de su dinamismo la clara proclamación de Jesucristo, salvación de Dios en la historia, revelación perfecta del Padre y realización de las promesas del Reino, con el cual Jesús se identifica totalmente. Este Jesús, Unigénito de Dios y Primogénito de María, se nos ha revelado como don supremo del amor del Padre, para iluminar a todo hombre, convocarlo al proyecto de su Reino, liberarlo de toda servidumbre por obra del Espíritu y ofrecerle la abundancia de la vida, que brota de la cruz como condición de glorificación y de señorío sobre toda criatura" (DTSD 441-442).

Esta evangelización ha de realizarse hoy dentro de unas nuevas coordenadas, entre las que sobresalen la sensibilidad hacia los signos de los tiempos y la dimensión de la justicia evangélica (DTSD 445-449). Ha de ir acompañada de un nuevo ardor, unos nuevos métodos y unas nuevas expresiones, aspectos que desarrolla ampliamente el documento (DTSD 456-470).

El segundo objetivo es la promoción humana, teniendo en cuenta su doble dimensión de liberación y de desarrollo integrales. En este punto se recuerda el inevitable conflicto social cuando se pretende construir una sociedad más humana y más justa. Se marca la importancia del compromiso social, colocándose en todo momento junto a los oprimidos. Se subraya la necesidad de la jerarquización de los intereses, la aportación de la doctrina social de la Iglesia, y la necesidad del discernimiento ético. Se insiste en la opción preferencial por los pobres y en la defensa de la dignidad inviolable de la persona humana. Se retoma el tema de la generalizada postura entre los cristianos del divorcio entre la fe y la vida, especialmente en el campo social, con graves repercusiones para todo el continente (DTSD 471-500).

El tercer objetivo es la evangelización de la cultura y de las culturas. Como ha escrito Scannone, "no puede haber promoción humana integral sin respeto a la identidad cultural y sin promoción cultural; a su vez, no puede

22. Véase el Discurso de Juan Pablo II a la II Asamblea Plenaria de la Pontificia Comisión para América Latina del 14/06/91, en DTSD pp. XVII-XXI. 
darse ésta sin una promoción humana integral, pues la cultura abarca todas las dimensiones, no sólo la de valores y antivalores éticos, sino también la de las expresiones y la de las estructuras sociales, políticas y económicas. De aquí que, con base en un concepto integral (ni funcionalista ni marxista) de cultura y a una concepción evangélica (no ideológica) de la opción por los pobres, Puebla no opone la opción pastoral por la evangelización de la cultura a la promoción humana, entendida sobre todo a partir de la opción por los pobres y su liberación, pues se trata de las dos caras de la misma moneda, o como del alma y el cuerpo de una misma opción evangélica por el hombre, sobre todo por el pobre" ${ }^{23}$.

La preocupación por este objetivo ya había aparecido en Medellín, en sus documentos sobre la juventud y sobre la educación, y posteriormente, más explícitamente, fue retomado por Puebla. Siguiendo la misma línea, se pronuncia el Documento de Trabajo.

Es un tema complejo y difícil, que viene a complicarse con la expresión de cultura cristiana, que se utiliza en el documento, aunque en su desarrollo se ofrece algunas explicaciones. Creo que hubiese sido preferible hablar de evangelización de la cultura y de las culturas, o de promoción de culturas evangelizadas, más comprensible para ambientes pluriculturales y en un contexto internacional de libertad y de pluralidad religiosa apoyado por el Vaticano II y repetidamente defendido por Juan Pablo II. El mismo documento para evitar confusiones, afirma que la Nueva Evangelización "no es una cruzada, no es el deseo de retornar a situaciones de cristiandad propias de otras épocas" (DTSD 437), habiendo reconocido anteriormente que "el ambiente favorecido por una sana secularización -no por el secularismo- ha ayudado a fortalecer la identidad católica y a precisar el sentido específico de su misión" (DTSD 108).

Dada la amplitud de este objetivo en el documento (DTSD 501-545), sólo quiero subrayar los dos valores que la Nueva Evangelización se propone impulsar en las diferentes culturas: el de la solidaridad y el de la vida: "Desde el interior de una sociedad plural, la Iglesia debe buscar caminos de diálogo, dándole contenido tangible a la cultura de la vida y a la cultura de la solidaridad, frente a una cultura de la muerte y de la dispersión. La evangelización nueva deberá aportar sentido a la vida de los latinoamericanos que, en el umbral del siglo XXI y del tercer milenio del cristianismo, requiere razones para creer, para esperar y para amar" (DTSD 123).

23. J. C. SCANNONE, "La promoción humana en la gestación de la nueva cultura", en AA.VV., "Hacia la cuarta conferencia", Bogotá 1992, p. 197. 
Cultura de la vida frente a la cultura de la muerte: "Una de las preocupaciones pastorales más apremiantes hoy en la Iglesia latinoamericana es la defensa de la vida en todas sus formas, etapas y situaciones. Particular atención merece la vida humana amenazada gravemente por el narcotráfico, la violencia, las campañas antinatalistas, la eutanasia y la destrucción de los recursos naturales que pertenecen a todos" (DTSD 286). A esta enumeración se podrían añadir otras causas, que aparecen en distintas partes del documento, de orden político, social y económico.

Cultura de la solidaridad frente a la cultura del individualismo insolidario y disperso. "La promoción humana no se limita a la abundancia de bienes materiales y tampoco a un ideal de consumo, sino que ha de ser contraído con los valores evangélicos de justicia, de solidaridad y de amor. Sólo entonces las multitudes empobrecidas podrán experimentar una vida digna de seres humanos y de hijos de Dios" (DTSD 362). En este contexto se manifiesta que, por la falta de solidaridad, América Latina padece una grave situación a nivel internacional, y una falta de integración tanto a nivel regional como a nivel interno de cada uno de los países, que oprime a los pobres y dificulta el proceso de un desarrollo integral (DTSD 144-149).

Dentro de esta línea de la solidaridad subraya el importante papel que una justa integración ha de jugar en cada uno de los países, y la necesidad del fortalecimiento de las políticas de integración entre todas las naciones de América Latina: "Es un imperativo histórico, para hacer frente a los problemas nacionales, porque consolida la postura de nuestros países en el escenario mundial. La integración no puede significar un nuevo estilo de explotación dentro del mismo continente, como tampoco una uniformidad que asfixie la originalidad de cada pueblo, sino la riqueza de la pluralidad dentro de un proyecto común que beneficie a todos los participantes" (DTSD 608-609).

\section{Una Iglesia para la Nueva Evangelización}

En el análisis del documento no he encontrado síntesis del nuevo modelo de Iglesia tan sugerentes y nítidas como las propuestas por Medellín y Puebla. De hecho, el tema lo afronta con amplios desarrollos. El primero cuando ofrece una mirada pastoral a la realidad eclesial en América Latina (DTSD 191-304). El segundo cuando, dentro de una reflexión teológica, presenta a la Iglesia como presencia de Jesucristo en el mundo (DTSD 378-409).

En esa parte, es especialmente sugerente al presentar a la Iglesia como comunión bajo el signo de la cruz (DTSD 400-402), y como comunidad para la misión, teniendo en cuenta los objetivos anteriormente apuntados (DTSD 403-409). 
Pero encontramos un tercer desarrollo, cuando nos habla del Espíritu que ha de animarnos, de los grandes desafíos, y de las opciones preferenciales (DTSD 567-678).

En esta parte se destacan cuatro características: Cultivar el ardor misionero, suscitar una adultez de fe, construir la unidad de la Iglesia, mantener la fortaleza con una esperanza dichosa, ya que "múltiples y arduos son los trabajos, pruebas y desafíos que habremos de afrontar, hasta que la nueva evangelización comience a despuntar como una primavera en América Latina" (DTSD 585).

\section{Hacia Santo Domingo}

Santo Domingo todavía no se ha celebrado. Sólo tenemos un documento de trabajo, elaborado por el CELAM tras múltiples consultas, y que será el punto de partida de la Conferencia. El marca una cuarta etapa, en estrecha continuidad y sintonía con el movimiento evangelizador que se inició en 1955, y al que hoy llamamos Nueva Evangelización.

Es, sin duda, un aporte importante. Pero no podemos olvidar que, en la actual situación internacional América Latina se encuentra con una fuerte carencia de modelos inspiradores, capaces de entusiasmar a los amplios sectores populares. Esto, sin duda, dificulta el trabajo de la Conferencia.

Sin embargo, dentro del mismo documento, se aportan algunas sugerencias que pueden ayudar en la orientación.

En primer lugar, se hace una clara alusión al crecimiento y multiplicación de movimientos contestatarios frente a la deshumanización de nuestra cultura. En efecto, constata que "frente a ello surgen reacciones que conllevan elementos de una nueva cultura, como el movimiento ecológico, el pacifismo, el renacer de la religiosidad, el reconocimiento de las minorías étnicas y culturales, y la tendencia a asociarse en sus distintos niveles. En todas estas nuevas manifestaciones socio-culturales -en cuanto buscan defender al hombre y a su integridad-puede y debe llegar a inculturarse el Evangelio" (DTSD 522).

Segundo: Frente al arrasante neoliberalismo, en muchos de nuestros pueblos ha ido desarrollándose durante estos años un fenómeno denominado neocomunitarismo de base. "La conciencia de la necesidad de la participación local, en el municipio y otros cuerpos intermedios entre el individuo y el Estado, revela un cambio de comprensión de la democracia, desde una simple acción electoral hacia otra donde la comunidad busca modos de organizarse para hacer frente a sus necesidades. Las marchas y otras formas de participación popular, activa y no violencia, son signos positivos" (DTSD 156-157). 
Tercero: También en las actuales circunstancias la Iglesia no debe olvidar que, en los pasados años de la represión, "ha sucedido con frecuencia que la Iglesia es el único espacio para defender los derechos del hombre y de la mujer ante sistemas políticos represores. Esto le ha acarreado conflictos con esos sistemas y con algunas clases sociales" (DTSD 288).

No podemos olvidar que la luz de la Nueva Evangelización ha de abrirse camino en muchas ocasiones entre parajes todavía sumidos en la oscuridad y el desconocimiento: "Se hace camino al andar".

\section{INCIDENCIA DE LA NUEVA EVANGELIZACION LATINOAMERICANA EN LA IGLESIA UNIVERSAL}

La Nueva Evangelización es claramente un movimiento eclesial autóctono y en su contenido de decidida factura latinoamericana, con una fecha oficial de origen, 1955. Pero, como ya hemos visto en nuestra introducción, a partir de diciembre de 1985 el Papa Juan Pablo II ha intentado transferirlo a todas las Iglesias presentes en los diferentes continentes de nuestro planeta, constituyéndolo en un proyecto y en un compromiso paneclesial teniendo en cuenta la nueva realidad socio-cultural de nuestro mundo y los desafíos que desde ella se plantean de cara al año 2.000, inicio del tercer milenio del cristianismo.

No es este el momento para abordar el análisis de la Nueva Evangelización como proyecto paneclesial, ni en las diferencias regionales que lógicamente comporta, ni en las dificultades y múltiples problemas que actualmente presenta a muchos niveles y por diversos motivos. Sólo pretendo apuntar -de una manera breve y casi con las características de un epílogo sugerente- la incidencia que la Nueva Evangelización latinoamericana ha tenido ya en la Iglesia universal y la que puede tener en el futuro. Hace unos años Bülhmann publicaba su célebre libro "La tercera Iglesia a las puertas". Creo que podemos afirmar que hoy, las Iglesias de América Latina, mediante el impulso de su Nueva Evangelización, han traspasado el umbral y han penetrado en el recinto.

\section{Las aportaciones de las Iglesias latinoamericanas}

Durante la segunda mitad de nuestro siglo, dos grandes acontecimientos produjeron profundos cambios en las Iglesias de América Latina. El primero fue la decidida modernización industrial del continente en el contexto de la guerra fría y bajo la rígida dependencia imperial de Estados Unidos. El segundo lo encontramos en la celebración del Concilio Vaticano II. Ambos hicieron surgir una nueva conciencia eclesial, tanto con relación a la comprensión del mundo, como también de la propia Iglesia. 
Sin duda, el descubrimiento más importante que hicieron las Iglesias latinoamericanas fue el del mundo de los pobres y los oprimidos, que surgió ante ellas como una luz nueva, capacitándolas para una interpretación más evangélica de la realidad y de la historia, y para una clarificación más radical de la misión de la propia Iglesia en el mundo. Por eso, hoy es frecuente oír en América Latina que los pobres nos evangelizan.

De hecho, el mundo de la pobreza siempre ha estado especialmente presente a la Iglesia desencadenando dentro de ella múltiples iniciativas de asistencia, misericordia y "caridad". Pero subyacía inconsciente el problema de cómo se le visualiza e interpreta. Durante siglos ha prevalecido la idea -idea ideologizada- que se trataba de un mundo marginado, atomizado, incapacitado, inculto, siempre necesitado de ser ayudado virtuosamente por los otros sectores de la sociedad.

Pero, de pronto, el mundo de la pobreza comenzó a tomar una nueva consistencia ante las Iglesias, gracias a las nuevas circunstancias en las que comenzaban a vivir.

Surgió, no como un submundo atomizado, sino como un cualificado mundo unificado por profundas corrientes de solidaridad interna, aunque con sus naturales deficiencias, muchas de ellas explicables por la situación misma en la que se encuentran los pobres.

Ser percibió que el mundo de la pobreza no tenía su origen primario en la incapacidad o debilidad de los pobres, sino principalmente en causas extrañas a ellas, localizables en los otros mundos. Comenzó a elaborarse un nuevo lenguaje teológico, en el que comenzó a hablarse de estructuras y culturas de pecado, tras las que se ocultaba el pecado de la insolidaridad y de los opresores, beneficiarios directos del mundo de la pobreza.

Se descubrió que en los ámbitos de la pobreza no subyacía la incultura -aunque sí falta de instrucción- sino unas originales culturas, provistas de su propia sabiduría, a las que en estos años comenzó técnicamente a designarse como las culturas de la pobreza. En ellas apareció una perspectiva y una óptica propia de ver el mundo, de interpretar la realidad global y el proceso de la historia.

En el mundo de los pobres no reinaban la apatía y el conformismo -aunque sí una espera que con astucia aguarda los momentos oportunos (DP 452) - sino un profundo y mantenido clamor por su verdadera liberación mediante la instauración de la justicia.

En la mayoría de la culturas latinoamericanas de la pobreza -a excepción de algunos grupos aborígenes y afroamericanos- resaltaba una marcada religiosidad, identificativa e impulsadora, compleja y difícil de interpretar, pero que progresivamente se fue cualificando como catolicismo popular (DP 444). 
Esta nueva comprensión de la pobreza y de los mundos de los pobres y de los oprimidos, condujo a las Iglesias de América Latina a una interpretación más profunda y realista de Jesús y de su mensaje evangélico, de las exigencias y del compromiso de la fe cristiana, de la misión integral de la Iglesia. Su consecuencia fue su opción preferencial por los pobres, lo que la exigía a penetrar en el interior de su mundo, sembrando la fe del Evangelio y participando en el dinamismo salvífico por una liberación integral de los oprimidos, por la instauración de un orden más justo y solidario, y por la promoción de una verdadera paz mesiánica.

En este ambiente surgieron la Teología de la Liberación y la de la Religiosidad Popular. En su propia estructuración la Iglesia buscó un neocomunitarismo eclesial de base, originándose las comunidades eclesiales de base, desarrollando un nuevo protagonismo y responsabilidad de los laicos tanto en la comunidad eclesial como en su específica misión en el mundo.

\section{Incidencias en el Magisterio de la Iglesia}

Sería necesaria una larga investigación para determinar las incidencias que la aportación latinoamericana ha tenido en el Magisterio universal y pontificio de los últimos años: sólo quiero recordar dos documentos, en los que no cabe duda de ninguna clase.

En uno de ellos leemos: "Como núcleo y centro de su Buena Nueva, Jesús anuncia la salvación, ese gran don de Dios que es liberación de todo lo que oprime al hombre, pero que es sobre todo liberación del pecado y del maligno" (EN 9). Y poco después añade: "Y al centro de todo, el signo al que El atribuye una gran importancia: los pequeños, los pobres son evangelizados, se convierten en discípulos suyos, se reúnen en su nombre en la gran comunidad de los que creen en El" (EN 12).

En el resto del documento son significativas sus referencias explícitas a la liberación -incluso con alusión explícita a los Obispos del Tercer Mundo, "con un acento pastoral en el que vibraban las voces de millones de hijos de la Iglesia que forman tales pueblos" (EN 30)-, a la religiosidad popular (EN 48), y a las comunidades eclesiales de base (EN 58).

El segundo documento es la Sollicitudo rei socialis, donde claramente el Papa hace un análisis de la realidad actual desde la perspectiva de las víctimas de la sociedad (SRS 11-26). Dirigiéndose a todos los hombres y mujeres sin excepción les pide que "convencidos de la gravedad del momento presente y de la respectiva responsabilidad individual pongamos por obra (...) las medidas inspiradas en la solidaridad y en el amor preferencial por los pobres. Así lo requiere el momento, así lo requiere sobre todo la dignidad de 
la persona humana, imagen indestructible del Dios Creador, idéntica en cada uno de nosotros. En este empeño deben ser ejemplo y guía los hijos de la Iglesia, llamados, según el programa anunciado por el mismo Jesús en la sinagoga de Nazareth, a anunciar a los pobres la buena nueva, a proclamar la liberación de los cautivos, la vista a los ciegos, para dar la libertad a los oprimidos y proclamar un año de gracia del Señor" (SRS 47).

\section{Incidencia en los proyectos regionalizados de la Nueva Evangelización}

Aunque los proyectos de Nueva Evangelización, fuera de América Latina, en general todavía se encuentran en un momento de gestación y asimilación en las diferentes Iglesias, sin embargo se les advierte sensibilizados por el mensaje emitido por las Iglesias latinoamericanas.

Esto es evidente en las Iglesias situadas en aquellas naciones y continentes que hasta ahora se han denominado del Tercer Mundo o en vías de desarrollo. El tema de la Evangelización Liberadora tuvo una gran acogida, aunque con las adaptaciones propias a los problemas de cada lugar.

Pero también se advierte en Europa. Ciertamente destacan los temas de la renovación de la fe, de la inculturación y adaptación de la Iglesia a la cultura moderna, de la comunión ecuménica, de la integración europea, etc. Pero simultáneamente se comienza a someter al continente a una severa crítica desde el mundo de las víctimas, de los pobres y de los oprimidos: desde los pueblos del tercer mundo, y desde el cuarto mundo, que dentro de su propio seno se está rápidamente generando. Curiosamente la Nueva Evangelización de Europa también percibe la urgencia de promover en el continente una cultura de la solidaridad, de la vida y de la transcendencia. Es el paso de Jesús haciendo su escandalosa propuesta a los ricos: "Cumple los mandamientos y, al mismo tiempo vende lo que tienes, dalo a los pobres y sígueme". Así aprendió en el encuentro ecuménico de Basilea y, más recientemente, en el Sínodo para Europa. Pienso que era la voz de las Iglesias de América Latina, que colabora en la evangelización interna de las Iglesias europeas, sensibilizándolas para una nueva y original evangelización de todo el continente.

A. GonZalez Dorado, S.J. 